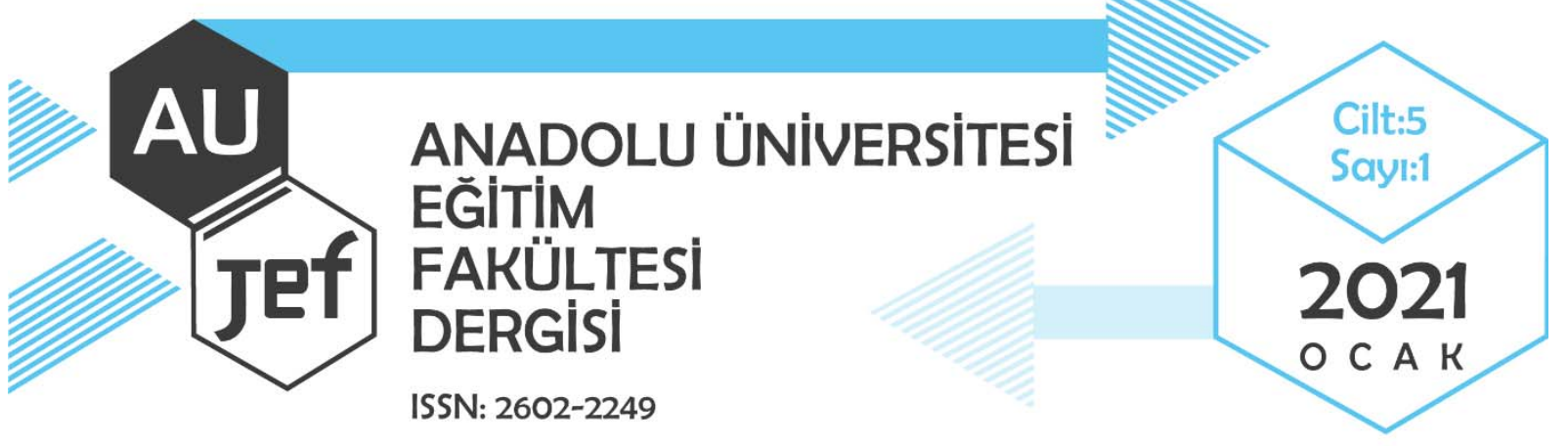

Açık ve Uzaktan Öğrenenlerin Öğrenme Ortam Tercihleriyle Kültürel Özellikleri Arasındaki İlişsi

\title{
The Relationship between Learning Environment Preferences and Cultural Characteristics of Open and Distance Learners
}

İrem ERDEM AYDIN ${ }^{1}$

Aslı TALTEKİN ${ }^{2}$

Makale Türü: Araştırma Makalesi ${ }^{3}$

Başvuru Tarihi: 19.11 .2020

Kabul Tarihi: 23.01 .2021

Atıf İçin : Erdem Aydın, İ. ve Taltekin, A. (2021). Açık ve uzaktan öğrenenlerin öğrenme ortam tercihleriyle kültürel özellikleri arasındaki ilişki. Anadolu Üniversitesi Ĕ̆itim Fakültesi Dergisi (AUJEF), 5(1), 1-21.

ÖZ: Bu çalışmanın amacı, açık ve uzaktan öğrenenlerin öğrenme ortam tercihlerinin Hofstede'nin kültürel boyutlarından Bireycilik ve Toplulukçuluk boyutuna göre farklılık gösterip göstermediğinin belirlenmesidir. $\mathrm{Bu}$ amaçla bir anket hazırlanmış, Anadolu Üniversitesi Açıköğretim Fakültesindeki 420 öğrenciye uygulanmıştır. Bu ankette öğrenenlerin kültürel özelliklerini belirleyebilmek için Bireycilik-Toplulukçuluk Ölçeği (IndividualismCollectivism Scale) ölçeği kulanılmıştır. Aynı zamanda ankette öğrencilere sistemin kendilerine sunduğu öğrenme ortamlarından hangilerini kullanmayı tercih ettikleri sorulmuştur. Araştırmada kesitsel araştırma modeli kullanılmıştır. Analiz sonuçlarına göre öğrencilerin en çok kullandıkları ortam, e-öğrenme hizmetlerindeki deneme sınavlarını uygulama olurken, en az kullanılan ortam ise, akademik danışmanlık etkinliklerine katılma olmuştur. Bunun yanında, açık ve uzaktan öğrenenlerin öğrenme ortam tercihlerinin bireycilik ve toplulukçuluk eğilimlerine göre farklılaştı̆ı gözlemlenmiş̧tir. Araştırma bireycilik eğilimi gösteren öğrenenlerin toplulukçuluk gösterenlere göre çevrimiçi deneme sınavlarını daha fazla tercih ettiklerini ortaya koymuştur. Bunun yanında, toplulukçuluk eğilimi gösteren öğrenenlerin bireycilik eğilimi gösterenlere göre eşzamanlı danışmanlık hizmetlerini daha fazla tercih ettikleri saptanmıştır.

Anahtar sözcükler: Açık ve uzaktan öğrenme, Hofstede'nin kültürel boyutları, bireycilik ve toplulukçuluk, öğrenme ortamları tercihi

ABSTRACT: The goal of this cross-sectional descriptive study is to examine whether the learning environment preferences of open and distance learners differ according to their cultural characteristic regarding the Hofstede's individualism-collectivism dimension. An online questionnaire was developed and administered to 420 students studying in Anadolu University's Open Education System (AOS). In this survey, the Individualism-Collectivism Scale was used to collect data about the cultural characteristics of the learners. The students were also asked to

\footnotetext{
${ }^{1}$ Doç.Dr. Anadolu Üniversitesi Açıköğretim Fakültesi, ieaydin@anadolu.edu.tr ORCID:0000-0003-3618-4123

${ }^{2}$ Şehit Metin Malkav Ortaokulu Seyhan / Adana ORCID:0000-0001-7898-719X
} 
indicate their preferences of the learning environments that AOS offers in the questionnaire. The results have shown that the most preferred environment was the online practice exams and the least one was the face-to-face academic counseling activities. Additionally, a significant difference was observed in the open and distance learners' learning environment preferences and their individualism and collectivism. More precisely, the study revealed that those who has more individualistic characteristics prefers the online trail exams more than those collectivist ones. On the other hand, those students who show more collectivist tendencies prefer synchronous counselling sessions more than those individualistic ones.

Keywords: Open and distance learning, cultural differences, individualism and collectivism, learning environment preferences 


\section{GİRIŞ}

Yaşadığımız dönem, bilginin üretilmesi, kullanılması ve aktarılmasına yönelik sürekli değişimlerin yaşandığ 1 bir zaman dilimidir. Bireylerin bilgi ve iletişim teknolojilerinde yaşanan bu gelişmelere uyum sağlama zorunluluğu, öğrenme ortamlarının bu gelişmelere göre güncellenmesi gereğini ortaya koymaktadır. Bu gelişmeler nedeniyle, sürekli eğitim ve yaşam boyu öğrenme temelinde kendi kendine öğrenebilme, güncel bilgiye ulaşıp takip edebilme yeterliliklerine sahip bireylere ihtiyaç duyulmaktadır. $\mathrm{Bu}$ bağlamda öğrenenin kendi hızında ilerlemesini, farklı kaynaklardan bilgiye ulaşmasını sağlayacak gelişmelerin öğrenme ortamlarına taşınması bir zorunluluk olarak karşımıza çıkmaktadır. Açık ve uzaktan öğrenme ortamları bu ihtiyaca cevap veren önemli seçeneklerden biridir. Aydın'a göre (2011) açık ve uzaktan öğrenme, öğrenenlerin öğrenme kaynaklarından ve birbirlerinden yer ve zaman olarak uzakta olduğu, etkileşimin uzaktan iletişim sistemleri çerçevesinde gerçekleştirildiği öğrenme süreci olarak tanımlanmaktadır. Gelişen teknoloji, yüz yüze olan öğrenme etkinliklerini zaman ve mekandan bağımsız herkesin ulaşabileceği bir düzeye getirmiştir (Holmberg, 1995; Moore \& Kearsley, 2012). Farklı coğrafi bölgelerden, yer ve zaman diliminden bireylerin aynı öğrenme sürecinde buluşuyor olması, öğrenenlerin kültürel özelliklerini dikkat edilmesi gereken bir değişken olarak karşımıza çıkarmaktadır.

Birçok araştırma kültürü, bireylerin, örgütlerin ve toplumların bilişim teknolojilerinin kullanımını etkileyen kilit faktör olarak ele almaktadır (Straud, 1994). Kültürel değerlerin, bilgi ve iletişim teknolojileri'nin benimsenmesinde etkili faktörlerden biri olduğunu gösteren çalışmalar vardır (Bagchi et al., 2003; Johns, Smith \&Strand, 2003; Sørnes et al., 2004). Son y1llarda çevrimiçi öğrenme uygulamalarının yaygınlaşmasıyla çok kültürlülüğün bu ortamlara nasıl yansıtılacağı ve öğrenme sürecindeki etkilerinin neler olduğu soruları dikkati çekmektedir. Kültürü öğretim tasarımı sürecinde dikkate alınması gereken bir değişken olarak karşımıza çıkarmaktadır. Bu nedenle farklı kültürlere sahip öğrenenlerin bir arada olduğu uzaktan öğrenme ortamlarında, öğrenenlerin kültürel farklılıklarına duyarlı ders tasarımlarının hazırlanması büyük önem taşımaktadır. Yapılan araştırmalar da kültürel farklılıkların, öğrenme sürecinde öğrenen başarısını etkileyen unsurlardan biri olduğunu göstermektedir (Davis, \& Sumara, 2010; Dincer, 2017, 2013; Heo, Lim \& Kim, 2010).

Hofstede (2001, s.9) kültürü, "Bir grubun ya da insan zümresinin üyelerini diğerlerinden ayıran zihinlerin ortak programlaması" şeklinde tanımlamakta ve kültürün altı boyuttan oluştuğunu dile getirmektedir. Bu boyutlar; güç mesafesi, belirsizlikten kaçınma, bireycilik-toplulukçuluk, erkeklikdişilik, uzun dönem-kısa dönem odağı ve sonradan eklediği hoşgörü-kısıtlamadan oluşmaktadır. Kültürlerarası farklılıkları anlamak için araştırmacılar tarafından en çok kullanılan boyutlardan biri, bireycilik-toplulukçuluktur (Cohen \& Avrahami, 2006, s. 891). Bu çalışmada da, Hofstede'nin kültüre ilişkin belirlediği boyutlarından sadece Bireycilik-Toplulukçuluk (B-T) boyutu ele alınmıştır. Hofstede (2001), bireyci topluluklarda kişilerin kendi hedefleri çerçevesinde hareket ettiklerini, birlikte hareket etme yerine rekabete eğilimi olduğu ve gruba ait olma duygularının düşük olduğunu, dile getirmektedir. Toplulukçu toplumlarda ise gruba daha çok önem verildiğini, grup içi aidiyet yüksek ve ortak amaçların önemli olduğunu dile getirmektedir.

Birbirlerinden farklı kültüre ait öğrenenler, uzaktan öğrenme sisteminde bir araya gelmektedir. Bu bağlamda da, öğrenenlerin bireycilik ve toplulukçuluk eğilimlerinin öğrenme ortamlarına olan yansımalarının neler olduğu cevap aranması gereken bir soru olarak karşımıza çıkmaktadır. Bu konuda yapılmış çeşitli araştırmalar vardır. Örneğin Gaspay, Legorreta ve Dardan (2009) çalışmalarında, öğrenenlerin bireycilik ya da toplulukçuluk özelliğine sahip olmalarının, uzaktan öğrenme ortamlarına ilişkin memnuniyetleri konusunda etkili olup olmadığını belirlemeye çalışmışlardır. Çalışma sonunda 
bu iki kültürel yapı arasında arasında belirgin farklılıklar ortaya çıkmış, bireycilik düzeyi yüksek olan öğrenenlerin uzaktan öğrenme konusundaki tutumlarının daha olumlu olduğu görülmüştür. Bireyci kültürden gelen öğrenenlerin bireysel çalışmaları daha çok tercih ettikleri görülmüştür. Uzaktan öğrenme ortamlarının öğrenenlere, öğrenme süreçlerinde daha bağımsız olma firsatını sunması, bu duruma bir gerekçe olarak gösterilebilir. Bir başka çalışmada, Shih ve diğerleri (2013) Tayvanlı (düşük bireycilik) ve Amerikalı (yüksek bireycilik) öğrencilerin kültürel özellikleriyle, çevrimiçi öğrenme biçimleri arasında bir ilişki olup olmadığına bakmışlardır. Araştırma sonunda Tayvanlı öğrencilerin, bütüncül bir yaklaşım içinde, somut materyallerle çalışmayı tercih ettikleri, bireysel çalışmak yerine grup çalışmalarına dahil olmayı seçtikleri görülmüştür. Amerikalı öğrencilerin ise, somut malzemeler kullanarak ve daha analitik davranarak, tek başlarına çalışma eğilimi gösterdikleri tespit edilmiştir. $\mathrm{Bu}$ çalışmalarda öğrenenlerin sahip oldukları kültürel yapıların öğrenme ortamındaki davranışlarını etkilediğini göstermektedir. Straud'da (1994), bireylerin, örgütlerin ve toplumların bilişim teknolojilerinin kullanımını etkileyen kilit bir faktör olduğunu ileri sürmektedir. Benzer çalışmalarda öğrenenlerin sahip oldukları kültürel özelliklerin, hem bireylerarası iletişim kurma biçimleri üzerinde etkili olduğunu, hem de öğrenme ortamlarında yeni iletişim teknolojilerinin kullanımı konusundaki tutumlarını etkilediğini ortaya koymuştur (Bagchi et al., 2003; Johns et al., Smith \& Strand, 2003; Sørnes et al., 2004).

Kültür üzerine yapılmış çalışmalar, genelde ülkeler arasındaki farklılık ve benzerlikleri ortaya koymayı hedef almaktadır. Öte yandan aynı ülkede yaşayan bireyler arasında da kültürel farklılıkların görülmesi söz konusu olabilmektedir. Bu konuda Triandis (2001, s. 909), bir ulusun toplulukçu ya da bireyci özellikler taşımasına rağmen bu boyutların o ülkede yaşayan bireyler arasında farklılık gösterebileceğini belirtmiştir. Türkiye'deki kültürel farkl1lıkların öğrenme ortam tercihleri üzerinde bir etkisinin olup olmadığı, öğrenme ortamlarının kültürel boyutlardan etkilenip etkilenmediği bir merak konusudur. Bu noktada anlamlı ve etkili bireysel öğrenme için, ders tasarımlarının farklı kültürel özelliklere sahip öğrenenlerin ihtiyaç ve beklentileri karşılayabilecek şekilde yapılması önem taşımaktadır. Açık ve uzaktan öğrenme ortamlarında öğrenme deneyimlerinin kalitesinin artırılabilmesi için, öğrenenlerin ortama katılımını sağlayan dinamiklerin neler olduğunun belirlenmesi çok önemlidir. Yapılan çalışmalar, katılımcıların kültürel farklılıkların öğrenme sürecinin nasıl algılandığı konusunda önemli bir belirleyici olduğunu göstermektedir (Kondratova et al., 2005, Li \& Kirkup, 2007; Oyserman et al., 2002; Chase et al., 2002). Bu bağlamda, açık ve uzaktan öğrenme ortamlarının tasarımında, öğrenenlerin sahip olduğu kültürel özelliklere karşı duyarlı olmak bir gereklilik olarak karşımıza çıkmaktadır. Bu önem doğrultusunda, bu çalışmanın amacı, Açıköğretim öğrencilerinin kültürel özelliklerinin (bireyci ya da toplulukçu) öğrenme ortam tercihleri konusuna bir etkisinin olup olmadığının belirlenmesidir. Bu genel amaç çerçevesinde aşağıdaki sorulara yanıt aranacaktır.

1. Hofstede'nin B-T alt boyutu ile uzaktan eğitim öğrencilerinin öğrenme ortam tercihleri arasında bir ilişki var mıdır?

2. Bireycilik boyutundaki öğrenenler hangi öğrenme ortamlarını tercih ederler?

3. Toplulukçuluk boyutundaki öğrenenler hangi öğrenme ortamlarını tercih ederler?

\section{YÖNTEM}

Bu çalışmada kesitsel araştırma modeli (Cross-sectional survey design) kullanılmıştır. Eğitim alanında en çok kullanılan araştırma modellerinden biri kesitsel araştırma modelidir. Bir olgunun ya da örneklemin belirli bir zamandaki halini gözlemlemeyi içeren araştırmalar kesitsel araştırmalar olarak 
adlandırılır (Creswell, 2012, s. 377). Araştırmacılar evrenden örneklem seçer, inceler ve örneklemden evrene genelleme yaparlar. Bu tür araştırmalarda veriler, anket ve mülakat olmak üzere iki şekilde toplanabilmektedir. Bu çalışmada ise veri toplama tekniği olarak anket kullanılmıştır. Anket Anadolu Üniversitesi Bilimsel Araştırma ve Yayın Etiği Kurulu tarafından 12.09.2018 tarihinde 88259 protokol numarasıyla onaylanmıştır.

\subsection{Evren ve Örneklem}

Anadolu Üniversitesi Açıköğretim sisteminde kayıtlı yaklaşı 1 milyon 400 bin öğrenci bulunmaktadır. Evrene ulaşmak maliyetli ve zaman alıcı olacağı için örneklemle çalışmak tercih edilmiştir. Çalışma için örneklem grubu, 2018-2019 eğitim-öğretim yılında kayıt yaptırmış öğrenciler arasından gönüllülük esasına dayanarak belirlenmiştir. Anket, güz döneminde Anadolu Üniversitesi Açıköğretim Fakültesi (AÖF) resmi sitesine (aof.anadolu.edu.tr) bir pop-up menüsü olarak sunulmuştur. $\mathrm{Bu}$ menüde öğrencilere çalışma hakkında kısa bir bilgi verilmiş, ardından ankete katılmayı kabul edip etmedikleri sorulmuştur ve 420 öğrenci çalışmaya katılmayı kabul etmiştir.

\subsection{Verilerin Toplanması}

Çalışmada, Anadolu Üniversitesi AÖF öğrencilerinin öğrenme ortam tercihleriyle kültürel yapıları arasında bir ilişkinin olup olmadığının belirlenmesi için öğrenenlere anket uygulanmıştır. Uygulanan anket üç bölümden oluşmaktadır. Birinci bölümde, öğrencilerin cinsiyeti, yaşı, kaçıncı sınıfta olduğu gibi demogafik bilgileri sorgulanmıştır. İkinci bölümde, öğrencilere Açıöğretim sisteminde yer alan ortamlar sunulmuş ve en çok kullandıkları ortamları işaretlemeleri istenmiştir. Üçüncü bölümde ise öğrenenlerin bireycilik ya da toplulukçuluk özelliklerinden hangisine sahip olduğu belirlenmeye çalışılmıştır. Bunun için Singelis ve diğerleri (1995) tarafından oluşturulmuş olan INDCOL (Individualism-Collectivism Scale) ölçeği kulanılmıştır. INDCOL ölçeği, psikometrik bakış açısından inançları, tutumları, davranışsal niyetleri ve davranışları kapsayan bir ölçektir ve 63 maddeden oluşmaktadır. Fletcher, Olekains ve Cieri De (1996) tarafından yapılan çalışmalar sonucu madde sayısı onaltıya düşürülmüştür. $\mathrm{Bu}$ maddelerin yedisi katılımcıların bireycilik, dokuzu toplulukçuluk özelliklerini ölçmektedir.

Ölçeğin orijinal dili İngilizcedir. Ölçek, İngilizce seviyesi çok iyi olan, araştırmacının da dahil olduğu, dört kişi tarafindan Türkçeye çevrilmiştir. Bu çalışmayı yapanlardan üçü İngilizce öğretmenidir. Ölçeğe son hali verilidikten sonra sonra pilot uygulaması yapılmıştır. Pilot çalışma için Anadolu Üniversitesi AÖF'de hala okuyan ya da AÖF'den mezun olmuş 49 kişiye anket uygulanmış ve SPSS programı ile geçerlik güvenirliklerine bakılmıştır. Bireycilik ve Toplulukçuluk ölçeğindeki ifadelerin ilgili faktörler altında dağılım gösterip göstermediğini saptamak amacıyla Açımlayıcı Faktör Analizi (AFA) yapılmıştır. AFA uygulamadan önce faktör modelinin uygunluğunu test etmek amaciyla KMO (Kaiser Meyer-Olkin) Barlett Küresellik Testi yapılmaktadır.

Elde edilen sonuçlara göre, KMO değerinin 0,80 ve üzerinde olması araştırmadaki verilerin AFA yapılabilmesi için uyum derecesinin yüksek olduğunu ifade etmektedir (Hair et al., 2014, s.102). Yapılan değerlendirme sonucunda Barlett's Küresellik testi sonucunun anlamlı olduğu ( $x^{2}: 1792,643$; df:66; $p<0,001)$ ve KMO örnekleme yeterliliği testinin 0,836 değerinde olduğu bulunmuştur. Buradan hareketle örneklem büyüklüğünün AFA uygulayabilmek için mükemmel derecede yeterli olduğunu söyleyebiliriz. $\mathrm{Bu}$ bağlamda, yapılan AFA'da faktörleştirme yöntemi olarak "temel bileşenler analizi (principal 
component analysis)" yapılmıştır. Döndürme yöntemi olarak ise Varimax kullanılmıştır. Ancak, yapılan bu analiz sonucunda üç ifadenin ("Benim mutluluğum daha çok çevremdekilerin mutluluğuna bağlıdır.", "İşimi başkalarından daha iyi yapmak benim için önemlidir.", "Bazı insanlar kazanmaya odaklıdır, ben onlardan biri değilim.", Yakın çevremdekilerin birbiriyle uyumunu muhafaza etmek benim için önemlidir) dağılımın birden fazla yapıda yüksek olması ve faktör yüklerinin 0,3'ten düşük olmasıyla nedeniyle analizden sırasıyla çıkartılmışlardır. Örneklem sayısı 300 ve üzerinde olduğu durumlarda ilgili ifadelerin faktör yük dağılımlarının en az 0,35 ve üzerinde olması istenilmektedir (Hair et al., 2014, s. 115).

İfadelerin çıkartılması sonucunda yeniden yapılan AFA sonucunda, faktörlere ait ifade yüklerinin 0,437 ile 0,822 arasında dağılım gösterdiği görülmüsşür. Bu bağlamda faktör yüklerinin yeterli düzeyde olduğu söylenebilir. Bununla birlikte, her faktörün sahip olduğu varyans oranlarının toplamda 54,315, yani \%54 olduğu belirlenmiştir. AFA yapılan bir çalışmada varyans değeri toplamının en az \%50 ve üzerinde olması istenmektedir (Seçer, 2015, s. 164). Bu bağlamda elde edilen \%54'lük değerin, AFA için uygun bir değer olduğu ifade edilebilir. Ayrıca, faktörler belirlendikten sonra yapılan Cronbach's Alpha güvenirlik analizleri sonucunda toplulukçuluk faktörü için güvenirlik skorunun 0,831 ; bireycilik faktörü için güvenirlik skorunun 0,761 olduğu saptanmıştır. Cronbach's Alpha güvenirlik skoru 0 ile 1 arasında bir değer almaktadır ve kabul edilebilir bir değerin en az 0,60 ve üzerinde olması gerekmektedir (Kalaycı, 2017, s. 405). Elde edilen güvenirlik skorlarından hareketle bu tez çalışmasının Bireycilik ve Toplulukçuluk ölçeğinin güvenilir olduğu ifade edilebilir.

\subsection{Verilerin Analizi}

Veri analizine geçilmeden önce öncü analizlerden biri olan ölçeğin çok değişkenli normalliği kontrol edilmiştir. Bunun için öncelikle, ölçek için kritik ki-kare değeri ve ifadelere ilişkin mahalanobis uzaklığı hesaplanmıştır. Daha sonra kritik ki-kare değeriyle ölçeklerin ifadelerine ilişkin mahalanobis uzaklığ 1 BoxPlot grafiğinde karşılaştırılmıştır. Yapılan karşılaştırma sonucunda toplamda 12 gözlemin çok değişkenli normallik için aykırı gözlem olduğu tespit edilmiş ve veri setinden çıkartılmalarına karar verilmiştir. Kalan 408 gözlemle veri setinin, bu tez çalışması için uygun olduğu söylenebilir. Verilerin analiz sürecinde de çalışmada katılımcıların öğrenme ortamlarını kullanma durumlarına göre dağılımlarını belirlemek için frekans ve yüzdeleri hesaplanmıştır. Bireycilik ve toplulukçuluk ölçeğine ilişkin ortalamalar ve standart sapmalar verilmiştir. Sonrasında katılımcıların bireycilik ve toplulukçuluk düzeyleri ile öğrenme ortamları arasındaki ilişkiyi belirlemek amacıyla ki-kare bağımsızlık testi uygulanmıştır.

\section{BULGULAR}

$\mathrm{Bu}$ bölümde sırasıyla katlımcıların demografik bilgilerine ilişkin veriler verilmiştir. Ardından katılımcıların öğrenme ortamlarına katılım durumlarına ilişkin frekans ve yüzde değerleri ifade edilmiştir. Daha sonra bireycilik ve toplulukçuluk ölçeğinde yer alan ifadelere ilişkin ortalamalar ve standart sapma değerleri verilmiştir. En son olarak, katılımcıların bireycilik ve toplulukçuluk düzeyleri ile öğrenme ortamları arasındaki ilişki ayrı ayrı tablolarda gösterilmiştir.

Yapılan analizler sonunda katılımcıların demografik verilerine ilişkin bilgiler şöyledir. Katılımcıların 158'i kadınlardan, 250'si erkeklerden oluşmaktadır. Katılımcılar yaş aralıkları açısından incelendiğinde \%33,6's1 18ve27 yaş arası, \%31,1'i 28ve37 yaş aras1, \%24,3'ü 38ve47 yaş arası ve \%11'i 
48 yaş ve üstünden oluştuğu görülmektedir. Eğitim gördükleri sınıflar açısından bakıldığında, \%75,2'si 1. sınıf, $\% 8,3$ 'ü 2. sınıf, $\% 13,7$ ’i 3. sınıf ve $\% 2,7$ ’i 4. sınıf öğrencisi oluşturmaktadır.

Katılımcıların öğrenme ortamlarına katılım durumlarına ilişkin analiz sonuçları Tablo 1'de verilmiştir.

Tablo 1: Katılımcıların Öğrenme Ortamlarını Kullanma Durumlarına Göre Dă̆ılımları

\begin{tabular}{|c|c|c|c|}
\hline \multirow[t]{2}{*}{ Öğrenme Ortamı } & & \multicolumn{2}{|c|}{ Katılma Durumu } \\
\hline & & Evet & Hayır \\
\hline \multirow[t]{2}{*}{ e-Öğrenme hizmetlerindeki deneme sınavlarını uygulama } & $\mathrm{N}$ & 292 & 116 \\
\hline & $\%$ & 71,6 & 28,4 \\
\hline \multirow[t]{2}{*}{ Ders kitabından çalışma } & $\mathrm{N}$ & 262 & 146 \\
\hline & $\%$ & 64,2 & 35,8 \\
\hline \multirow[t]{2}{*}{ e-Öğrenme hizmetlerindeki alıştırma sorularında yer alan uygulamalardan yararlanma } & $\mathrm{N}$ & 250 & 158 \\
\hline & $\%$ & 61,3 & 38,7 \\
\hline \multirow[t]{2}{*}{ e-Kitap okuma } & $\mathrm{N}$ & 208 & 200 \\
\hline & $\%$ & 51 & 49 \\
\hline \multirow[t]{2}{*}{ e-Öğrenme hizmetlerindeki konu anlatım videolarını izleme } & $\mathrm{N}$ & 223 & 185 \\
\hline & $\%$ & 54,7 & 45,3 \\
\hline \multirow[t]{2}{*}{ e-Seminer hizmetlerindeki soru çözümlerinden yararlanma } & $\mathrm{N}$ & 99 & 309 \\
\hline & $\%$ & 24,3 & 75,7 \\
\hline \multirow[t]{2}{*}{ e-Seminer hizmetlerindeki ders anlatımından yararlanma } & $\mathrm{N}$ & 72 & 336 \\
\hline & $\%$ & 17,6 & 82,4 \\
\hline \multirow[t]{2}{*}{ e-Öğrenme hizmetlerindeki sesli kitabı dinleme } & $\mathrm{N}$ & 47 & 361 \\
\hline & $\%$ & 11,5 & 88,5 \\
\hline \multirow[t]{2}{*}{ Ünite ile ilgili TV programlarını izleme } & $\mathrm{N}$ & 78 & 330 \\
\hline & $\%$ & 19,1 & 80,9 \\
\hline \multirow[t]{2}{*}{ e-Öğrenme hizmetlerindeki sesli kitap uygulamasından yararlanma } & $\mathrm{N}$ & 34 & 374 \\
\hline & $\%$ & 8,3 & 91,7 \\
\hline \multirow[t]{2}{*}{ Akademik danışmanlık etkinliklerine katılma } & $\mathrm{N}$ & 24 & 384 \\
\hline & $\%$ & 5,9 & 94,1 \\
\hline \multirow[t]{2}{*}{ e-Öğrenme hizmetlerindeki danışmanlık hizmetlerinden yararlanma } & $\mathrm{N}$ & 28 & 380 \\
\hline & $\%$ & 6,9 & 93,1 \\
\hline
\end{tabular}


Tablo 1 incelendiğinde katılımcıların AÖF öğrenme ortamlarından en sık kullandıklarının sırasıyla \%71,6 ile "e-öğrenme hizmetlerindeki deneme sınavlarını uygulama", \%64,2 ile "ders kitabından çalışma", \%61,3 ile "e-öğrenme hizmetlerindeki alıştırma sorularında yer alan uygulamalardan yararlanma" olduğu görülmektedir. En az kullanılan ortamların ise, "akademik danışmanlık etkinliklerine katılma" (\%5,9), "e-öğrenme hizmetlerindeki danışmanlık hizmetlerinden yararlanma" (\%6,9), "e-öğrenme hizmetlerindeki sesli kitap uygulamasından yararlanma" $(\% 8,3)$ maddelerinin olduğu görülmektedir.

Tablo 2: Bireycilik ve Toplulukçuluk Ölçeğine ve Ifadelerine İlişkin Ortalamalar ve Standart Sapmaları

\begin{tabular}{|c|c|c|}
\hline Faktörler ve İlgili İfadeler & Ort. & S.Sapma \\
\hline Toplulukçuluk & 3.89 & $\mathbf{0 , 6 7}$ \\
\hline Maddi güçlük içinde olan bir akrabama imkanlarım ölçüsünde yardım ederim & 4,12 & 085 \\
\hline İş arkadaşlarımın iyiliği benim için önemlidir & 4,11 & 0,85 \\
\hline Bir iş arkadaşım ödül alsa gurur duyarım & 4,02 & 0,90 \\
\hline Başkalarıyla işbirliği yaptığım zaman kendimi iyi hissederim & 3,94 & 0,81 \\
\hline Komşularımla ufak tefek şeyleri paylaşmak hoşuma gider & 3,86 & 1,00 \\
\hline Benim için zevk başkalarıyla vakit geçirmektir & 3,33 & 1,02 \\
\hline Bireycilik & 3,00 & 0,78 \\
\hline Başkaları benden daha başarılı olduğunda rahatsız olurum & 3,79 & 1,10 \\
\hline Başkası benden daha başarılı olduğunda gerilir ve hırs yaparım & 3,47 & 1,16 \\
\hline Kazanmak her şeydir & 3,13 & 1,24 \\
\hline Rekabet olmadan iyi bir toplum düzeni kurulmaz & 2,79 & 1,16 \\
\hline Başkalarıyla rekabet edebileceğim ortamlarda çalışmak hoşuma gider & 2,54 & 1,15 \\
\hline Rekabet doğanın kanunudur & 2,34 & 1,13 \\
\hline
\end{tabular}

Tablo 2 incelendiğinde, toplulukçuluk faktörünün ortalamasının 3,89 olduğu görülmektedir. Bu faktördeki en yüksek ortalamaya sahip ifadelerin de "Maddi güçlük içinde olan bir akrabama imkanlarım

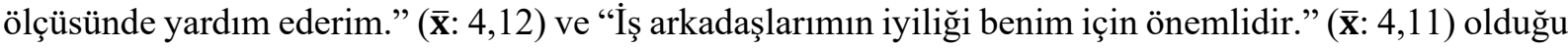
görülmektedir. En düşük ortalamaya sahip ifadelerin ise "Komşularımla ufak tefek şeyleri paylaşmak

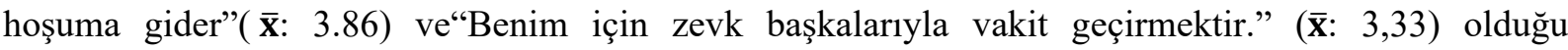
görülmektedir. Bireycilik faktörünün ortalaması 3,00'tür. "Başkaları benden daha başarılı olduğunda

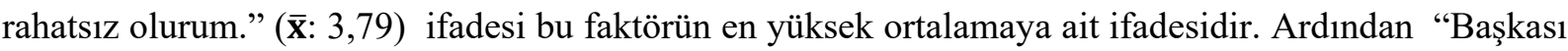




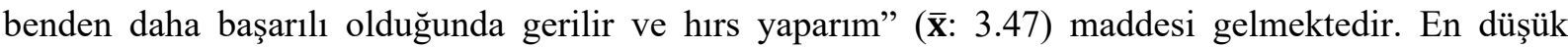
ortalamaya sahip olan ifadelerin ise "Başkalarıyla rekabet edebileceğim ortamlarda çalışmak hoşuma

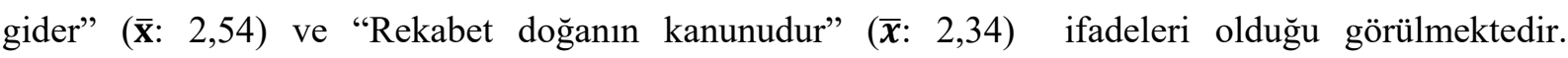
Katılımcıların bireycilik düzeyleri ile öğrenme ortamları arasındaki ilişkiyi tespit edebilmek amacıyla ki-kare bağımsızlık testi uygulanmıştır. Sonuçlar Tablo 3'de gösterilmektedir.

Tablo 3: Bireycilik düzeyleri ile öğrenme ortamları arasındaki ilişki

\begin{tabular}{|c|c|c|c|c|c|}
\hline \multicolumn{2}{|c|}{ Öğrenme Ortamı } & \multicolumn{2}{|c|}{ Bireycilik Düzeyi } & \multirow[t]{2}{*}{$x^{2}$} & \multirow[t]{2}{*}{$P$} \\
\hline & & Düşük & Yüksek & & \\
\hline \multicolumn{6}{|c|}{ Ders kitabından çalışma } \\
\hline \multirow{2}{*}{ Evet } & $\mathbf{N}$ & 108 & 113 & 2,151 & 0,161 \\
\hline & $\%$ & 26,5 & 27,7 & & \\
\hline \multirow{2}{*}{ Hayır } & $\mathbf{N}$ & 64 & 123 & & \\
\hline & $\%$ & 15,7 & 30,1 & & \\
\hline \multirow{2}{*}{ Toplam } & $\mathbf{N}$ & 172 & 236 & & \\
\hline & $\%$ & 42,2 & 57,8 & & \\
\hline \multicolumn{6}{|c|}{ e-Öğrenme hizmetlerindeki deneme sınavlarını uygulama } \\
\hline \multirow{2}{*}{ Evet } & $\mathbf{N}$ & 113 & 179 & 5,037 & $0,027^{*}$ \\
\hline & $\%$ & 27,7 & 43,8 & & \\
\hline \multirow{2}{*}{ Hayır } & $\mathbf{N}$ & 59 & 57 & & \\
\hline & $\%$ & 14,5 & 14,0 & & \\
\hline \multirow{2}{*}{ Toplam } & $\mathbf{N}$ & 172 & 236 & & \\
\hline & $\%$ & 42,2 & 57,8 & & \\
\hline \multicolumn{6}{|c|}{ e-Öğrenme hizmetlerindeki alıştırma sorularında yer alan uygulamalardan yararlanma } \\
\hline \multirow{2}{*}{ Evet } & $\mathbf{N}$ & 97 & 153 & 2,983 & 0,100 \\
\hline & $\%$ & 23,8 & 37,5 & & \\
\hline \multirow{2}{*}{ Hayır } & $\mathbf{N}$ & 75 & 83 & & \\
\hline & $\%$ & 18,4 & 20,3 & & \\
\hline \multirow{2}{*}{ Toplam } & $\mathbf{N}$ & 172 & 236 & & \\
\hline & $\%$ & 42,2 & 57,8 & & \\
\hline \multicolumn{6}{|c|}{ e-Kitap okuma } \\
\hline \multirow{2}{*}{ Evet } & $\mathbf{N}$ & 95 & 113 & 2,151 & 0,161 \\
\hline & $\%$ & 23,3 & 27,7 & & \\
\hline \multirow{2}{*}{ Hayır } & $\mathbf{N}$ & 77 & 123 & & \\
\hline & $\%$ & 18,9 & 30,1 & & \\
\hline \multirow{2}{*}{ Toplam } & $\mathbf{N}$ & 172 & 236 & & \\
\hline & $\%$ & 42,2 & 57,8 & & \\
\hline
\end{tabular}


Tablo 3 (Devam): Bireycilik düzeyleri ile ögrrenme ortamları arasındaki ilişki

\begin{tabular}{|c|c|c|c|c|c|}
\hline \multicolumn{6}{|c|}{ e-Öğrenme hizmetlerindeki konu anlatım videolarını izleme } \\
\hline \multirow{2}{*}{ Evet } & $\mathbf{N}$ & 88 & 135 & \multirow[t]{6}{*}{1,465} & \multirow[t]{6}{*}{0,229} \\
\hline & $\%$ & 21,6 & 33,0 & & \\
\hline \multirow{2}{*}{ Hayır } & $\mathbf{N}$ & 84 & 101 & & \\
\hline & $\%$ & 20,6 & 24,8 & & \\
\hline \multirow{2}{*}{ Toplam } & $\mathbf{N}$ & 172 & 236 & & \\
\hline & $\%$ & 42,2 & 57,8 & & \\
\hline \multicolumn{6}{|c|}{ e-Öğrenme hizmetlerindeki soru çözümlerinden yararlanma } \\
\hline \multirow{2}{*}{ Evet } & $\mathbf{N}$ & 47 & 52 & 1,516 & 0,243 \\
\hline & $\%$ & 11,6 & 12,7 & & \\
\hline \multirow{2}{*}{ Hayır } & $\mathbf{N}$ & 125 & 184 & & \\
\hline & $\%$ & 30,6 & 45,1 & & \\
\hline \multirow{2}{*}{ Toplam } & $\mathbf{N}$ & 172 & 236 & & \\
\hline & $\%$ & 42,2 & 57,8 & & \\
\hline \multicolumn{6}{|c|}{ e-Öğrenme hizmetlerindeki ders anlatımından yararlanma } \\
\hline \multirow{2}{*}{ Evet } & $\mathbf{N}$ & 31 & 41 & 0,029 & 0,896 \\
\hline & $\%$ & 7,6 & 10,0 & & \\
\hline \multirow{2}{*}{ Hayır } & $\mathbf{N}$ & 141 & 195 & & \\
\hline & $\%$ & 34,6 & 47,8 & & \\
\hline \multirow{2}{*}{ Toplam } & $\mathbf{N}$ & 172 & 236 & & \\
\hline & $\%$ & 42,2 & 57,8 & & \\
\hline \multicolumn{6}{|c|}{ e-Öğrenme hizmetlerindeki sesli kitabı dinleme } \\
\hline \multirow{2}{*}{ Evet } & $\mathbf{N}$ & 24 & 23 & 1,728 & 0,210 \\
\hline & $\%$ & 5,9 & 5,6 & & \\
\hline \multirow{2}{*}{ Hayır } & $\mathbf{N}$ & 148 & 213 & & \\
\hline & $\%$ & 36,3 & 52,2 & & \\
\hline \multirow{2}{*}{ Toplam } & $\mathbf{N}$ & 172 & 236 & & \\
\hline & $\%$ & 42,2 & 57,8 & & \\
\hline \multicolumn{6}{|c|}{ Ünite ile ilgili TV programlarını izleme } \\
\hline \multirow{2}{*}{ Evet } & $\mathbf{N}$ & 37 & 41 & 1,102 & 0,310 \\
\hline & $\%$ & 9,1 & 10,0 & & \\
\hline \multirow{2}{*}{ Hayır } & $\mathbf{N}$ & 135 & 195 & & \\
\hline & $\%$ & 33,1 & 47,8 & & \\
\hline \multirow{2}{*}{ Toplam } & $\mathbf{N}$ & 172 & 236 & & \\
\hline & $\%$ & 42,2 & 57,8 & & \\
\hline
\end{tabular}


Tablo 3 (Devam): Bireycilik düzeyleri ile öğrenme ortamları arasındaki ilişki

\begin{tabular}{|c|c|c|c|c|c|}
\hline \multicolumn{6}{|c|}{ e-Öğrenme hizmetlerindeki sesli kitap uygulamasından yararlanma } \\
\hline \multirow{2}{*}{ Evet } & $\mathbf{N}$ & 16 & 18 & 0,365 & 0,589 \\
\hline & $\%$ & 4,0 & 4,4 & & \\
\hline \multirow{2}{*}{ Hayır } & $\mathbf{N}$ & 156 & 218 & & \\
\hline & $\%$ & 38,2 & 53,4 & & \\
\hline \multirow{2}{*}{ Toplam } & $\mathbf{N}$ & 172 & 236 & & \\
\hline & $\%$ & 42,2 & 57,8 & & \\
\hline \multicolumn{6}{|c|}{ Akademik danışmanlık etkinliklerine katılma } \\
\hline \multirow{2}{*}{ Evet } & $\mathbf{N}$ & 12 & 12 & 0,643 & 0,524 \\
\hline & $\%$ & 2,9 & 2,9 & & \\
\hline \multirow{2}{*}{ Hayır } & $\mathbf{N}$ & 160 & 224 & & \\
\hline & $\%$ & 39,3 & 54,9 & & \\
\hline \multirow{2}{*}{ Toplam } & $\mathbf{N}$ & 172 & 236 & & \\
\hline & $\%$ & 42,2 & 57,8 & & \\
\hline \multicolumn{6}{|c|}{ e-Öğrenme hizmetlerindeki danışmanlık hizmetlerinden yararlanma } \\
\hline \multirow{2}{*}{ Evet } & $\mathbf{N}$ & 17 & 11 & 4,246 & $0,047^{*}$ \\
\hline & $\%$ & 4,2 & 2,7 & & \\
\hline \multirow{2}{*}{ Hayır } & $\mathbf{N}$ & 155 & 225 & & \\
\hline & $\%$ & 38,0 & 55,1 & & \\
\hline \multirow{2}{*}{ Toplam } & $\mathbf{N}$ & 172 & 236 & & \\
\hline & $\%$ & 42,2 & 57,8 & & \\
\hline
\end{tabular}

$* p<0,05$.

Yukarıda yer alan Tablo 3, katılımcıların bireycilik ölçeğine verdiği yanıtlarla öğrenme ortamlarını kullanma durumları arasında bir ilişki olup olmadığını göstermektedir. Tablo incelendiğinde, bireycilik düzeyinin ortalardan "e-öğrenme hizmetlerindeki deneme sınavlarını uygulama" ve "eöğrenme hizmetlerindeki danışmanlık hizmetlerinden yararlanma" maddeleri ile aralarında anlamlı bir ilişki olduğu görülmektedir. Bu maddelerden "e-öğrenme hizmetlerindeki deneme sınavlarını uygulama"ya evet diyenlerin çoğunluğu $(\% 43,8)$ Yüksek Bireyciyken hayır diyenlerin çoğunluğunun $(\% 14,5)$ Düşük Bireyci olduğu görülmektedir. Bunun yanında "e-öğrenme hizmetlerindeki deneme sınavlarını uygulama" ile bireycilik düzeyi arasında anlamlı bir ilişki bulunmuştur $(0,027 \mathrm{p}<0,05)$. Diğer madde de"e-öğrenme hizmetlerindeki danışmanlık hizmetlerinden yararlanma"ya evet diyenlerin çoğunluğu Düşük Bireyciyken $(\% 4,2)$, hayır diyenlerin çoğunluğu $(\% 55,1)$ Yüksek Bireycidir. Son olarak, "e-öğrenme hizmetlerindeki danışmanlık hizmetlerinden yararlanma" ile bireycilik düzeyi arasında anlamlı bir ilişki bulunmuştur $(0,047 \mathrm{p}<0,05)$. Bu maddeler dışında kalan maddeler ile bireycilik düzeyi arasında ise anlamlı bir ilişki bulunamamışırı $(\mathrm{p}>0,05)$. Katılımcıların toplulukçuluk düzeyleri ile öğrenme ortamları arasındaki ilişkiyi tespit edebilmek amacıyla ki-kare bağımsızlık testi uygulanmıştır. Sonuçlar Tablo 4'de gösterilmektedir. 
Tablo 4: Toplulukçuluk düzeyleri ile öğrenme ortamları arasındaki ilişki

\begin{tabular}{|c|c|c|c|c|c|}
\hline \multirow[t]{2}{*}{ Öğrenme Ortamı } & & \multicolumn{2}{|c|}{ Toplulukçuluk Düzeyi } & \multirow[t]{2}{*}{$x^{2}$} & \multirow[t]{2}{*}{$P$} \\
\hline & & Düşük & Yüksek & & \\
\hline \multicolumn{6}{|c|}{ Ders kitabından çalışma } \\
\hline & $\mathbf{N}$ & 56 & 206 & & \\
\hline Evet & $\%$ & 13,7 & 50,5 & & \\
\hline Hayır & $\mathbf{N}$ & 38 & 108 & & \\
\hline \multirow[t]{3}{*}{ Toplam } & $\%$ & 9,3 & 26,5 & 1,145 & 0,327 \\
\hline & $\mathbf{N}$ & 94 & 314 & & \\
\hline & $\%$ & 23 & 77 & & \\
\hline \multicolumn{6}{|c|}{ e-Öğrenme hizmetlerindeki deneme sınavlarını uygulama } \\
\hline & $\mathbf{N}$ & 63 & 229 & & \\
\hline Evet & $\%$ & 15,4 & 56,2 & & \\
\hline Hayır & $\mathbf{N}$ & 31 & 85 & & \\
\hline \multirow[t]{3}{*}{ Toplam } & $\%$ & 7,6 & 20,8 & 1241 & 0,297 \\
\hline & $\mathbf{N}$ & 94 & 314 & & \\
\hline & $\%$ & 23 & 77 & & \\
\hline \multicolumn{6}{|c|}{ e-Öğrenme hizmetlerindeki alıştırma sorularında yer alan uygulamalardan yararlanma } \\
\hline & $\mathbf{N}$ & 45 & 205 & & \\
\hline Evet & $\%$ & 11 & 50,3 & & \\
\hline Hayır & $\mathbf{N}$ & 49 & 109 & & \\
\hline \multirow[t]{3}{*}{ Toplam } & $\%$ & 12 & 26,7 & 9,246 & $0,004 * *$ \\
\hline & $\mathbf{N}$ & 94 & 314 & & \\
\hline & $\%$ & 23 & 77 & & \\
\hline \multicolumn{6}{|l|}{ Kitap okuma } \\
\hline & $\mathbf{N}$ & 42 & 166 & 1,940 & 0,196 \\
\hline Evet & $\%$ & 10,3 & 40,7 & & \\
\hline Hayır & $\mathbf{N}$ & 52 & 148 & & \\
\hline \multirow[t]{3}{*}{ Toplam } & $\%$ & 12,7 & 36,3 & & \\
\hline & $\mathbf{N}$ & 94 & 314 & & \\
\hline & $\%$ & 23 & 77 & & \\
\hline \multicolumn{6}{|c|}{ e-Öğrenme hizmetlerindeki konu anlatım videolarını izleme } \\
\hline & $\mathbf{N}$ & 42 & 175 & & \\
\hline Evet & $\%$ & 11,7 & 42,9 & & \\
\hline Hayır & $\mathbf{N}$ & 46 & 139 & 0,636 & 0,479 \\
\hline \multirow[t]{3}{*}{ Toplam } & $\%$ & 11,3 & 34,1 & & \\
\hline & $\mathbf{N}$ & 94 & 314 & & \\
\hline & $\%$ & 23 & 77 & & \\
\hline
\end{tabular}


Tablo 4 (Devam): Toplulukçuluk düzeyleri ile öğrenme ortamları arasındaki ilişsi

\begin{tabular}{|c|c|c|c|c|c|}
\hline \multicolumn{6}{|c|}{ e-Öğrenme hizmetlerindeki soru çözümlerinden yararlanma } \\
\hline & $\mathbf{N}$ & 15 & 85 & \multirow{6}{*}{4,587} & \multirow{6}{*}{0,039} \\
\hline Evet & $\%$ & 3,7 & 20,6 & & \\
\hline Hayır & $\mathbf{N}$ & 79 & 230 & & \\
\hline \multirow[t]{3}{*}{ Toplam } & $\%$ & 19,3 & 56,4 & & \\
\hline & $\mathbf{N}$ & 94 & 314 & & \\
\hline & $\%$ & 23 & 77 & & \\
\hline \multicolumn{6}{|c|}{ e-Öğrenme hizmetlerindeki ders anlatımından yararlanma } \\
\hline & $\mathbf{N}$ & 16 & 56 & \multirow{6}{*}{0,033} & \multirow{6}{*}{0,856} \\
\hline Evet & $\%$ & 3,9 & 13,7 & & \\
\hline Hayır & $\mathbf{N}$ & 78 & 258 & & \\
\hline \multirow[t]{3}{*}{ Toplam } & $\%$ & 19,1 & 63,3 & & \\
\hline & $\mathbf{N}$ & 94 & 314 & & \\
\hline & $\%$ & 23 & 77 & & \\
\hline \multicolumn{6}{|c|}{ e-Öğrenme hizmetlerindeki sesli kitabı dinleme } \\
\hline & $\mathbf{N}$ & 10 & 37 & \multirow{6}{*}{0,093} & \multirow{6}{*}{0,855} \\
\hline Evet & $\%$ & 2,4 & 9,1 & & \\
\hline Hayır & $\mathbf{N}$ & 84 & 277 & & \\
\hline \multirow[t]{3}{*}{ Toplam } & $\%$ & 20,6 & 67,9 & & \\
\hline & $\mathbf{N}$ & 94 & 314 & & \\
\hline & $\%$ & 23 & 77 & & \\
\hline \multicolumn{6}{|c|}{ Ünite ile ilgili TV programlarını izleme } \\
\hline & $\mathbf{N}$ & 170 & 61 & \multirow{6}{*}{0,084} & \multirow{6}{*}{0,881} \\
\hline Evet & $\%$ & 4,1 & 15 & & \\
\hline Hayır & $\mathbf{N}$ & 77 & 253 & & \\
\hline \multirow[t]{3}{*}{ Toplam } & $\%$ & 18,9 & 62 & & \\
\hline & $\mathbf{N}$ & 94 & 314 & & \\
\hline & $\%$ & 23 & 77 & & \\
\hline \multicolumn{6}{|c|}{ e-Öğrenme hizmetlerindeki sesli kitap uygulamasından yararlanma } \\
\hline & $\mathbf{N}$ & 8 & 26 & \multirow{6}{*}{0,005} & \multirow{6}{*}{0,943} \\
\hline Evet & $\%$ & 2,0 & 6,4 & & \\
\hline Hayır & $\mathbf{N}$ & 86 & 288 & & \\
\hline Toplam & $\%$ & 21 & 70,6 & & \\
\hline & $\mathbf{N}$ & 94 & 314 & & \\
\hline & $\%$ & 23 & 77 & & \\
\hline
\end{tabular}


Tablo 4 (Devam): Toplulukçuluk düzeyleri ile öğrenme ortamları arasındaki ilişki

\begin{tabular}{|c|c|c|c|c|c|}
\hline \multicolumn{6}{|c|}{ Akademik danışmanlık etkinliklerine katılma } \\
\hline & $\mathbf{N}$ & 11 & 13 & \multirow{6}{*}{7,474} & \multirow{6}{*}{$0,011^{*}$} \\
\hline Evet & $\%$ & 2,7 & 3,2 & & \\
\hline Hayır & $\mathbf{N}$ & 83 & 301 & & \\
\hline \multirow[t]{3}{*}{ Toplam } & $\%$ & 20,3 & 73,8 & & \\
\hline & $\mathbf{N}$ & 94 & 314 & & \\
\hline & $\%$ & 23 & 77 & & \\
\hline \multicolumn{6}{|c|}{ e-Öğrenme hizmetlerindeki danışmanlık hizmetlerinden yararlanma } \\
\hline & $\mathbf{N}$ & 5 & 23 & & \\
\hline Evet & $\%$ & 1,2 & 5,6 & & \\
\hline Hayır & $\mathbf{N}$ & 89 & 291 & 0,455 & 0,644 \\
\hline \multirow[t]{3}{*}{ Toplam } & $\%$ & 21,8 & 71,4 & & \\
\hline & $\mathbf{N}$ & 94 & 314 & & \\
\hline & $\%$ & 23 & 77 & & \\
\hline
\end{tabular}

$* * p<0,01 ; * p<0,05$.

Yukarıda yer alan Tablo 4, katılımcıların toplulukçuluk ölçeğine verdiği yanıtlarla öğrenme ortamlarını kullanma durumları arasında bir ilişki olup olmadığını göstermektedir. Tablo incelendiğinde, toplulukçukluk düzeyi ile ortamlar arasındaki "e-öğrenme hizmetlerindeki alıştırma sorularında yer alan uygulamalardan yararlanma", "e-seminer hizmetlerindeki soru çözümlerinden yararlanma" ve "akademik danışmanlık etkinliklerine katılma" maddeleri ile aralarında anlamlı bir ilişki olduğu görülmektedir.

Öğrenme ortamlarından "e-öğrenme hizmetlerindeki alıştırma sorularında yer alan uygulamalardan yararlanma"maddesine evet diyenlerin çoğunluğu $(\% 50,3)$ Yüksek Toplulukçu iken, hayır diyenlerin çoğunluğu da $(\% 26,7)$ Yüksek Toplulukçu'dur. Diğer taraftan, Düşük Toplulukçuların çoğunluğu (\%12) "e-öğrenme hizmetlerindeki alıştırma sorularında yer alan uygulamalardan yararlanma"ya hayır derken, Yüksek Toplulukçuların çoğunluğu buna evet demiştir. "E-öğrenme hizmetlerindeki alıştırma sorularında yer alan uygulamalardan yararlanma" ile toplulukçuluk düzeyi arasında anlamlı bir ilişki bulunmuştur $(0,004 \mathrm{p}<0,01)$.

"E-seminer hizmetlerindeki soru çözümlerinden yararlanma"ya evet diyenlerin çoğunluğu $(\% 20,6)$ Yüksek Toplulukçu iken, hayır diyenlerin çoğunluğu da $(\% 56,4)$ Yüksek Toplulukçudur. Diğer taraftan, Düşük Toplulukçuların çoğunluğu $(\% 19,3)$ "e-seminer hizmetlerindeki soru çözümlerinden yararlanma"ya hayır derken, Yüksek Toplulukçuların çoğunluğu da hayır demiştir. "E-seminer hizmetlerindeki soru çözümlerinden yararlanma" ile toplulukçuluk düzeyi arasında ise anlamlı bir ilişki bulunmuştur $(0,039 \mathrm{p}<0,05)$. “Akademik danışmanlık etkinliklerine katılma”ya evet diyenlerin nispeten çoğunluğu $(\% 3,2)$ Yüksek Toplulukçu iken, hayır diyenlerin çoğunluğu $(\% 73,8)$ Yüksek Toplulukçu'dir. Düşük Toplulukçuların çoğunluğu $(\% 20,3)$ "akademik danışmanlık etkinliklerine katılma"ya hayır derken, Yüksek Toplulukçu de hayır demiştir. "Akademik danışmanlık etkinliklerine katılma" ile toplulukçuluk düzeyi arasında anlamlı bir ilişki bulunmuştur $(0,011 \mathrm{p}<0,05)$. Bu ifadeler dışında kalan öğrenme ortamları ile toplulukçuluk düzeyi arasında anlamlı bir ilişki bulunamamıştır $(p>0,05)$. 


\section{TARTIŞMA ve SONUÇ}

Hofstede'nin Bireycilik-Toplulukçuluk eğilimleri ile uzaktan eğitim öğrencilerinin öğrenme ortam tercihleri arasında bir ilişkinin olup olmadığının belirlenmeye çalışıldığ çalışmada, kesitsel tarama modeli kullanılmıştır. Araştırma anketi 2018-2019 eğitim-öğretim yılında kayıt yaptırmış olan ve çalışmaya katılmaya gönüllü bireylere uygulanmıştır. Katılımcıların genel demografik özelliklerine bakıldığında katılımcıların çoğu erkeklerden oluşmaktadır ve büyük oranda 18-37 yaş aralığında olduğu görülmektedir. Eğitim seviyelerine bakıldığında katılımcıların \%75.2'si 1. sınıf öğrencileri olduğu dikkati çekmektedir. Katılımcıların büyük bölümü interneti iyi ve çok iyi kullanabilme düzeyine sahip olduğunu belirtirken neredeyse hemen hepsi her gün interneti kullandığını dile getirmiştir.

Analiz sonuçları incelendiğinde bütün ortamların öğrenenler tarafından kullanıldığı fakat yoğunluğun belirli ortamlar üzerinde toplandığı dikkati çekmektedir. En çok kullanılan ortam "eögrenme hizmetlerindeki deneme sinavlarını uygulama" olurken, en az kullanılan ortam "akademik danışmanlık etkinliklerine katılma"dır. Deneme sınavları, Açıöğretim öğrencilerinin sınavlara hazırlık yapabilmeleri için, kendilerini gerçeğe en yakın biçimde değerlendirebilme firsatı buldukları sınavlardır. $\mathrm{Bu}$ nedenle, öğrencilerin gerçek sınav benzetimlerinin yapıldığı bu sınav uygulamalarından yararlanmak istemeleri, beklenen bir sonuç olacaktır. Diğer sonuç, öğrenenlerin akademik danışmanlık hizmetlerinden yararlanmayı çok tercih etmediklerini göstermektedir. Sistemin öğrenenlere sunduğu ortamı incelediğimizde, gerek ders anlatımı, gerek soru çözümü gerekse deneme sınavlarıyla oldukça çeşitliliği barındırdığı görülmektedir. Öğrenenler teknoloji yardımıyla öğreticilerle, gerek eşzamanlı gerekse eşzamansız bir araya gelebilme olanağ da bulabilmektedirler. Bu nedenle öğrenenlerin yüzyüze Akademik Danışmanlık Hizmeti veren merkezlere gitmeyi gerekli bulmadıkları düşünülebilir.

Açık ve uzaktan öğrenenlerin bireycilik ve toplulukçuluk eğilimleri ile öğrenme ortam tercihleri arasındaki ilişkiye bakıldığında bazı ortamların bu boyutlar ile anlamlı bir ilişki içinde olduğu görülmüştür. Ortamlar içinde "e-ögrenme hizmetlerindeki deneme sinavlarını uygulama" ve "eöğrenme hizmetlerindeki danışmanlık hizmetlerinden yararlanma” maddeleri ile bireycilik arasında anlamlı bir ilişki görülmüştür. Alanyazında yapılan bazı çalışmalarda, çevrimiçi öğrenmenin bireycilere uygun olduğu da söylenmektedir (Gobbo et al., 2004; Bing \& Ai-Ping, 2008). Bireycilik eğilimine sahip olanların, grup aidiyetlerinin düşük olduğu, gruptan bağımsız bireysel amaçları doğrultusunda hareket etmeyi tercih ettikleri ifade edilmiştir ( Kondratova et al., 2005). Bu bağlamda bireycilik eğilimi yüksek olan öğrenenlerin, bireysel bir öğrenme modeli olan çevrimiçi öğrenme ortamına katılmayı tercih etmeleri, beklenen bir sonuç olacaktır. Tapanes, Smith, ve White'nin (2009, s.32) yaptıkları çalışmada da bireycilik eğilimi olan öğrenenlerin çevrimiçi derslere katılma konusunda toplulukçu kişilerden daha istekli oldukları görülmüştür.

Bunun yanında, "e-öğrenme hizmetlerindeki alıştırma sorularında yer alan uygulamalardan yararlanma", "e-seminer hizmetlerindeki soru çözümlerinden yararlanma" ve "akademik danışmanlı etkinliklerine katılma" maddeleri ile toplulukçuluk eğilimi arasında anlamlı bir ilişki bulunmuştur. Eseminerlerde öğrenenlere canlı dersler ile sesli, görüntülü, eş zamanlı danışmanlık, konu anlatımı, soru çözümleri hizmeti verilmektedir. Öğrenciler öğretim elemanlarıyla eş zamanlı bir araya gelerek onlara soru sorma firsatı bulabilmektedir. Akademik danışmanlık hizmetlerinde ise öğrenenler, bazı dersler için öğretim elemanıyla yüz yüze biraraya gelerek etkileşim kurabilmektedir. Her iki etkinliğin diğer ortamlardan farklılığı, öğrenenlere kendilerini yüzyüze sınıf ortamına benzer, topluluk içinde hissedebilecekleri bir ortam sunulmasıdır. Toplulukçu eğilimi olan öğrenenler, grup çalışmalarına ve kişilerarası etkileşime daha yatkındırlar (Speece, 2012, s. 7). Bu bağlamda, toplulukçu bireylerin yüzyüzeye benzer öğrenme ortamlarını daha çok kullanmalarının nedeninin, kendilerini bulundukları

Anadolu Üniversitesi Ĕ̆itim Fakültesi Dergisi (AUJEF), 5(1), 1-21 
gruba ait hissetmek istemeleri olduğu düşünülebilir. Öte yandan alanyazında yapılan çalışmalar $(\mathrm{Ku} \&$ Lohr, 2003, s. 101; Tapanes \& Smith, \& White, 2009, s.32) araştırmanın sonuçlarıla karşılaştırıldığında, tam tersi bir sonuç ortaya koymaktadır. Ku ve Lohr (2003) yaptıkları çalışmada, ilk defa çevrimiçi ders alacak öğrenciler üzerinde bir durum çalışması yapmışlardır. Çinli (toplulukçu) ve Amerikalı (bireyci) öğrencileri bir araya getiren bu çalışmada, Çinli öğrenciler yüz yüzeyken kendilerini ifade etmekte zorlandıklarını ama çevrimiçi ortamda herkesin eşit olduklarını düşündüklerinden daha rahat olduklarını belirtmişlerdir Diğer bir ifadeyle alanyazında yapılan benzer çalışmalarda toplulukçu eğilimi olan öğrenenlerin yüzyüze yerine e-öğrenme ortamlarını tercih ettikleri görülmektedir. Biz de ise toplulukçu eğilimi olan öğrenenlerin yüzyüzeye benzer öğrenme süreçlerini daha çok tercih ettikleri dikkati çekmektedir. Birbirine benzemeyen bu sonuçların temelini, araştırmaların yapıldığ toplumların kültürel farklılığında arayabiliriz. Bizim eğitim sistemimizde, öğrenme süreçlerinin geleneksel anlayışla yürütüldüğü görülmektedir. Diğer bir değişle öğrenci bilgiyi alan, öğretmen de bu bilgiyi öğrenciye aktaran konumundadır (Senemoğlu, 2004). Bu anlamda öğrenenlerin ilkokuldan beri süregelen bu öğrenme alışkanlığını e-öğrenme süreçlerine de taşıdığı söylenebilir. Öğrenenler bu alışkanlıklar gereği yüzyüzeye benzer öğrenme ortamlarını tercih etme yönünde oldukları ileri sürülebilir.

Bunun dışında ortamların genel kullanımına bakıldığında da toplulukçu eğilimi olanların ortamları daha çok kullandığı görülmektedir. E-öğrenme ortamlarında toplulukçu öğrenciler akranlarıyla iletişim kurabilirler. Akran desteğinin yüksek düzeyde olması, toplulukçu gruplarda bireylerin özgüvenini arttırmaktadır (Chu \& Chu, 2010, s. 147). Çeşitli araştırmalarda toplulukçuların, teknoloji tabanlı öğrenme ortamlarından bireycilere göre daha çok zevk aldıkları ortaya konmaktadır (Gaspay\& Legorreta \& Dardan, 2009; Chu \& Chu, 2010). Bir e-öğrenme sisteminin kullanışlılığı konusunda yapılmış olan bir çalışmada (Downey et al., 2005), araştırmacılar, toplulukçu toplumlardaki kişilerin bireyci toplumlardaki kişilere göre bu sistemi daha kullanışıı buldukları ve sistemden daha memnun kaldıkları sonucuna ulaşmışlardır. Yapılan araştırmanın sonuçlarıda bu anlamda alanyazında yapılan çalışmaların sonuçlarını destekler nitelikte olduğu görülmektedir. 


\section{KAYNAKLAR}

Arifin, W. N. (2015). The graphical assessment of multivariate normality ssing spss. Education in Medicine Journal, 7(2), 71-75.

Aycan, Z. \& Kanungo, R.N. (2000). Toplumsal kültürün kurumsal kültür ve insan kaynakları uygulamaları üzerine etkileri. İçinde: Z. Aycan (Ed.), Türkiye'de Yönetim, Liderlik ve Insan Kaynakları Uygulamaları (ss. 25-53). Ankara: Türk Psikologlar Derneği Yayınları.

Ayas, T. \& Horzum, M. B. (2011). Exploring the teachers' cyber bullying perception in terms of various variables. International Online Journal of Educational Sciences, 3(2), 619-6.

Aydın, C. H. (2011). Açık ve uzaktan öğrenme: öğrenci adaylarının bakışaçısı. Ankara: Pegem Akademi.

Bagchi, K., Cerveny, R., Hart, P. \& Peterson, M. (2003). The influence of national culture in information technology product adoption. In Proceedings of the 9th Americas conference on information systems, 957-965.

Başbay, A. \& Bektaş, Y. (2010). Çok kültürlülük bağlamında öğretim ortamı ve öğretmen yeterlikleri. Eğitim ve Bilim, 34(152), 30-43.

Bing, W.\& Ai-Ping, T.( 2008). The influence of national culture toward learner' interaction in the online learning environment: A comparative analysis of Shanghai TV University (China) and Wawasan Open University (Malaysia). The Quarterly Review of Distance Education, 9(3),327-339.

Canbek, O. N. G. (2015). Uzaktan öğretme ve öğrenme: uzaktan eğitimin temelleri. Açıköğretim Uygulamaları ve Araştırmaları Dergisi, 1(2), 102-111.

Chase, M., Macfadyen, L, Reeeder, K.\&Roche, J.(2002). Intercultural challenges in networked learning: Hard Technologies meet soft skills. First Monday, 7(8).doi:105210/fm.v7i8.975.

Chang, T. T., Wang, X. \& Lim, J. (2002). Cross-cultural communication, media and learning processes in asynchronous learning networks. In Proceedings of the 35th Annual Hawaii International Conference on System Sciences, 113-122.

Chu, R. J. \& Chu, A. Z. (2010). Multi-level analysis of peer support, Internet self efficacy and e-learning outcomesThe contextual effects of collectivism and group potency. Computers \& Education, 55(1), 145-154.

Cohen, A. \& Avrahami, A. (2006). The relationship between individualism, collectivism, the perception of justice, demographic characteristics and organisational citizenship behaviour. The Service Industries Journal, 26(8), 889-901.

Crewel, J. W. (2002). Educational research: planning, conducting, and evaluating quantitative. Upper Saddle River, NJ: Prentice Hall.

Davis, B.\& Sumara, (2010).If things were simple: Complexity in education. Journal of Evaluation in Clinical Practice, 16(4),856-860.doi:10.11/j.1365 2753.2010.01499.xPMID:20659215.

Dincer, D. (2017). Açık ve uzaktan öğrenme bağlamında kültürel boyutlar teorisi. Volkan Yüzer (Ed.). Açık ve uzaktan ögrenmede bireysel farklılıklar içinde (s. 1-22).Açıköğretim Fakültesi Yayınları. ISBN: 978-97506-2194-9.

Doğar, N. (2016). Türk Sineması örneklemi bağlamında Türkiye'nin batı ile kültürel yakınlaşma serüveni. Uluslararası Bilimsel Araştırmalar Dergisi (IBAD), 3(1), 304-318.

Downey, S., Wentling, R. M., Wentling, T. \& Wadsworth, A. (2005). The relationship between national culture and the usability of an e-learning system. Human Resource, Development International, 8(1), 47-64.

Ercan, H. (2008). Genç yetişkinlerin aşk biçemleri ve benlik tipleri. (Doktora tezi), Ankara Üniversitesi, Eğitim Bilimleri Enstitüsü, Ankara. 
Fay, B. (2001). Çağdaş sosyal bilimler felsefesi çok kültürlü bir yaklaşım. İstanbul: Mart Matbaacılık.

Fletcher, L., Olekains, M. \& Cieri De, H. (1996). Cultural differences in conflict resolution: Individualism and Collectivism in the Asia-Pacific Region. Department of Management Working Paper in Organizational Studies. Parkville, VIC, the University of Melbourne.

Gaspay, A., Legorreta, L. \& Dardan, S. (2009). The role of the individualism-collectivism dimension in distance learning environments: An empirical study. In System Sciences, 2009. HICSS'09. 42nd Hawaii International Conference on, 1-9.

Gobbo, L. D., Nieckoski, M., Rodman, R. \& Sheppard, K. (2004). Virtual limits: Multicultural dimensions of online education. International Educator, 13(3), 30-39.

Göregenli, M. (1995). Kültürümüz açısından bireycilik-toplulukçuluk eğilimleri: Bir başlangıç çalışması. Türk Psikoloji Dergisi, 10 (35), 1-14

Gürbüz, S. \& Sığrı, Ü. (2012). Kariyer Çapalarının Temel Benlik Değerlendirmesi ve Kültürel değerleri ile İlişkisi:Türkiye ve ABD Karşılaştırması. 20. Ulusal Yönetim ve Organizasyon Kongresi'nde Sunulan Bildiri, İzmir.

Hair, J. F., Black, W. C., Babin, B. J. \& Anderson, R. E. (2014). Multivariate data analysis (pearson new international edition). USA: Pearson Educated Limited.

Heo, H., Lim, K. Y. \& Kim, Y. (2010). Exploratory study on the patterns of online interaction and knowledge coconstruction in project-based learning. Computers \& Education, 55, 383-1392.

Hofstede, G. (2001). Culture's consequences: comparing values, behaviors, institutions, and organizations across nations. London: Sage Publications.

Hofstede, G. (1986). Cultural differences in teaching and learning. International Journal of intercultural relations, 10(3), 301-320.

Holmberg, B. (1995). Theory and practice of distance education. Second edition. London:Routledge.

Johns, S. K., Smith, M.\&Strand, C. A. (2003). How culture affects the use of information technology. Accounting Forum, 27(1), 84-109.

Kalaycı, Ş. (2017). Spss uygulamalı çok değişkenli istatistik teknikleri. Ankara: Dinamik Akademi Yayın Dağıtım.

Kondratova A. A., Dubrovsky Y. V., Antoch M. P., \&Kondratov R. V. (2010). Circadian clock proteins control adaptation to novel environment and memory formation. Aging (Albany NY), 2, 285-297.

Ku, H. Y. \& Lohr, L. L. (2003). A case study of Chinese student's attitudes towardtheir first online learning experience. Educational Technology Research and Development, 51(3), 95-102.

Li,N., \& Kirkup, G (2007). Gender and cultural differences in internet use: a study of China and the UK. Computers\&Education, 48, 301-317.

Moore, M., Kearsley, G. (2012). Distance education: A systems view of online learning. Belmont, CA: Wadsworth.

Nakip, M. (2013). Pazarlamada araştırma teknikleri. İstanbul: Seçkin Yayıncılık 2013, s. 428.

Oyserman, D., Coon, H. M. \& Kemmelmeier, M. (2002). Rethinking individualism and collectivism: evaluation of theoretical assumptions and meta-analyses. Psychological Bulletin, 128 (1), 3.

Özdikmenli-Demir, G. \& Sayıl, M. (2009). Individualism-collectivism and conceptualizations of interpersonal relationships among Turkish children and their mothers. Journal of Social and Personal Relationships, 26(4), 371-387. 
Seçer, İ. (2015). Spss ve lisrel ile pratik veri analizi. Ankara: Anı Yayıncılık.

Senemoğlu, N. (2004). Gelişim, ögrenme ve ögretim: kuramdan uygulamaya (10. bask1). Ankara: Gazi Kitabevi

Singelis, T. M., Triandis, H. C., Bhawuk, D. S. \& Gelfand, M. (1995). Horizontal and vertical dimensions of individualism and collectivism: A Theoretical and measurement refinement. Cross-Cultural Research, $29,240-275$.

Straud, D. W. (1994). The effect of culture in IT diffusion: E-mail and fax in Japan and the U.S. Information Systems Research, 5(1), 23-47.

Sørnes, J.-O., Stephens, K. K., Stre, A. S. \& Browning, L. D. (2004). The reflexivity between ICTs and business culture: Applying Hofstede's theory to compare Norway and the United States. Informing Science Journal, $7,1-30$.

Speece, M. (2012). Learning Style, Culture and Delivery Mode in Online Distance Education. Online Submission.

Triandis, H. C. (2001). Individualism-collectivism and personality. Journal of personality, 69(6), 907-924.

Tapanes, M. A., Smith, G. G. \& White, J. A. (2009). Cultural diversity in online learning: A study of the perceived effects of dissonance in levels of individualism/collectivism and tolerance of ambiguity. The Internet and Higher Education, 12(1), 26-34.

Wasti, A. ve Erdil, S.E. (2007), Bireyci ve Toplulukçuluk Değerlerinin Ölçülmesi: Benlik Kurgusu ve INDCOL Ölçeklerinin Türkçe Geçerlemesi. Yönetim Araştırmaları Dergisi, 7(1), 39-66.

Yıldız, S. G. M., (2018). Kültürün mekânsal değişimler üzerindeki etkisi. Gazi İktisat ve Isşletme Dergisi, 4(3), 173-184. 


\section{EXTENDED ABSTRACT}

Advances in communication and internet technologies have uncovered the reflections of technology on social, cultural and economic life. As one of the driving forces of the changes in social life, technology also causes continuous transformation in the production, use and transfer of information/knowledge. With the effect of this transformative power of technology, the need for individuals, who are capable of learning by themselves, and accessing and following up-to-date information on the basis of continuous education and lifelong learning is rapidly increasing. The necessity for individuals to adapt social changes makes it necessary for individuals to update learning environments according to the advances in ICT. In this context, it is a necessity to bring the developments, which will enable learners to progress at their own pace, access information from different sources, and move beyond the boundaries of time and space, into the learning environments. Open and distance learning is one of the noteworthy alternatives that meet this need.

Open and distance learning allows learners from various time zones and location, from different cultures and countries come together in the same learning process. Cultural characteristics of the learners emerge as a variable that should be taken into account while creating ODL processes and environments. Studies show that culture affects attitudes towards the adoption and use of information and communication technologies. In distance learning environments where learners from different cultures take place, it is of great importance to design a course fits the learners' cultural differences and their individual learning habits. This is especially important for preparing learning activities that promote active participation and increase the quality of learning processes.

Culture, on the other hand, Hofstede defines culture as "joint programming of minds that distinguish members of a group or group of people from others" and categorize cultural characteristics under six dimensions: power distance, uncertainty avoidance, individualism- collectivism, masculinityfemininity, long-term orientation, and indulgence. One of the most used dimensions by researchers to understand cross-cultural differences is individualism-collectivism. Individualism refers to a society in which individuals are expected to take care of only themselves and their immediate families. On the contrary, in a collectivist society, individuals can expect their relatives or members of a particular ingroup to look after them in exchange for unquestioning loyalty. Individualism vs. collectivism characteristics of the learners may influence their preferences and actions in a learning environment. For instance, those students may perform better in teams than others. So, it is important to learn more about the learners' characteristics regarding the individualism vs. collectivism dimension of the cultural differences. This study addressed this need. In other words, the study intended to discover the Turkish distance learners' cultural characteristics on individualism versus collectivism dimension and the relationship between these characteristics and the learners' preferences of the instructional media.

A cross-sectional survey design was employed in this study and it was conducted in the distance programs offered by Anadolu University. An online survey was developed and conducted during Fall semester of 2018-2019 academic year. It was presented as a pop-up message on the Anadolu University Open Education Faculty Web site (aof.anadolu.edu.tr). The pop-up message first elaborated some details of the study, including the goal, and then asked the learners' willingness to participate the study. Total 420 students voluntarily took part in the study. The survey instrument included three section: first section covered questions concerning the participants' demographic characteristics, such as age, gender, program, etc. while second section presented the instructional media offered in Anadolu and asked to indicate their preferences of using these media as well as how frequently they use each medium. Final section of the instrument helped the researchers collect data about the students' individualism vs. collectivism characteristics. This final section consisted of the INDCOL (Individualism-Collectivism 
Scale) developed by Singelis, et al. (2015). Descriptive anayses (frequencies and percentages) were conducted to explore the learners' usage and preference of instructional media. Similarly means and standard deviations were derived from the individualism and collectivism scale. Additionally, a chisquare test of independence was applied to determine the relationship between the students' individualism and collectivism characteristics and their preference and usage of instructional media in distance courses.

The analyses have revealed that the most frequently used medium was the trial exams in e-learning services, while the least used one was the academic consultancy opportunities. The participants specifically noted that they did not prefer to use the academic consultancy services (evening face-to-face classes as educational support system) Anadolu offers them. Th study additionally, uncovered the relationship between the students' preference and usage of some specific media and their individualism vs. collectivism characteristics. For instance, those participants students who have more individualistic characteristics prefer trail exams and the academic support in the learning management platform. Also, those students tend to be more collectivist prefer the synchronous question and answer sessions and the online practices. Moreover, the study showed that those collectivist students use the online support services more than the individualistic ones. Briefly, the results of this study supported the available literature on online learners' individualism vs collectivism characteristics. Namely, the available literature presented that those students who have tendency to be more collectivist were more satisfied with online learning, felt more comfortable for the opportuny to interact with their peers in online courses, and due to peer support their self-esteem levels did increase. Similar results have observed in this study too. 